\title{
La crítica de la modernidad desde el Caribe: lecturas negras de la filosofía (blanca) de la historia ${ }^{1}$
}

\author{
Florencia Bonfiglio \\ Investigadora del CONICET Profesora de la Universidad Nacional de La Plata \\ Universidad Nacional de La Plata - CONICET, La Plata, Argentina \\ https://orcid.org/0000-0002-5397-2626 \\ flobonfiglio@hotmail.com
}

\section{Resumen}

El texto reflexiona, en primer lugar, sobre el eurocentrismo de las teorías de la secularización y su desatención a la incidencia de la Conquista, el colonialismo y la esclavitud en el surgimiento de la modernidad. Luego, a partir de algunas definiciones claves del ensayo caribeño anticolonialista (C. L. R. James, Depestre, Fanon), las cuales ponen de manifiesto la «blancura» de la moderna filosofía de la historia que justificó la convivencia de la esclavitud con la emancipación del hombre, se considera la «racialización» del progreso como una de las modulaciones más evidentes de la paradójica dinámica secularización/sacralización que caracteriza a la modernidad. Se observa que, mientras el ensayo anticolonialista afrocaribeño se apropia de un aparato de pensamiento marxista que permite deconstruir los mitos occidentales (el progreso, la raza, los ideales «universales» de la Revolución francesa), las creencias, sin embargo, retornan en la literatura a través del imaginario emancipatorio de la negritud y la experiencia política (secularizada, resacralizada) de la diáspora africana como sujeto revolucionario.

Palabras clave: caribeño; ensayo; modernidad; negritud; secularización.

1 Procedencia del artículo: Este artículo es resultados de mi investigación individual sobre la literatura caribeña (CONICET) y de mi investigación en el proyecto grupal del Programa de incentivos (UNLP) titulado "Literatura y Secularización en América Latina: para una crítica política de la modernidad occidental", dirigido por el Dr. E. Foffani. 


\section{The critique of modernity from the Caribbean: black readings in (white) philosophy of history}

\section{Abstract}

This paper reflects, first, on the Eurocentric condition of the theories of secularization and their disregard of the incidence of the conquest, colonialism and slavery on the rise of Modernity. By looking at some key definitions of the Caribbean anti-colonialist essay (C. L. R. James, Depestre, Fanon) which point at the "whiteness" inherent in the modern philosophy of history that justified the coexistence of slavery with the emancipation of man, we then posit the "racialization" of Progress as one of the most evident modulations of the paradoxical dynamics secularization/sacralization which characterizes Modernity. Lastly, we observe that while the Afro-Caribbean anti-colonialist essay has recourse to a Marxist body of thought which enables it to deconstruct Western myths (Progress, Race, the "universal" ideals of the French Revolution), beliefs return, however, in literary form through Negritude's imaginary of emancipation and the political (secularized, resacralized) experience of the African diaspora as revolutionary subject.

Keywords: Caribbean; essay; modernity; negritude; secularization.

Recibido: 17 de junio del 2020. Aprobado: 03 de julio del 2020

Artículo de reflexión

https://doi.org/10.25100/poligramas.v0i51.10812

\section{¿Cómo citar este artículo en MLA? - How to quote this article in MLA?}

Bonfiglio, Florencia. "La crítica de la modernidad desde el Caribe: lecturas negras de la filosofía (blanca) de la historia" Poligramas 51 (2020): n. pag. Web. Fecha de acceso (día, mes en mayúscula y abreviado, y año). 


\section{El eterno retorno de las creencias}

Todas las formas de explotación se parecen. Todas van a buscar su necesidad en algún decreto bíblico (Fanon, Piel negra 72).

Una de las operaciones críticas constitutivas del pensamiento latinoamericano y caribeño, que lo autorizan en el intercambio mundial (y desigual) del conocimiento, consiste, a veces a nuestro pesar, en calibrar las grandes teorías metropolitanas (el uso del verbo calibrar, pienso, es oportuno: convoca la figura de la «razón occidental» como un arma, instrumento de dominio). Entre las muchas ideas iluminadoras de un ensayo imprescindible en este sentido, titulado Descarga acústica (2010), el puertorriqueño Julio Ramos nos recuerda que el pensamiento latinoamericano, ante la teoría de la secularización weberiana, ha problematizado desde los años 30 del siglo pasado la unidimensionalidad de su conceptualización. Para Ramos, el planteo del cubano Fernando Ortiz sobre el fenómeno de la transculturación recusaba ya "las teorías unidimensionales de la 'difusión' y de la secularización ilustrada”, cuando sostenía que el tiempo "sagrado" del tabaco impregnaba "el tiempo de la racionalización y la imaginación secular moderna" (60). De modo paradojal, según Ramos, "se estimulaba la modernidad mediante la introducción -inicialmente prohibida o muy controlada- de productos que provenían de historias sagradas y rituales, como el tabaco, el opio o la hoja de coca-" (60). Lo interesante de la observación de Ramos es no solo el carácter paradójico de la modernidad occidental, que se nutre -mientras se aparta- de lo sagrado (tal dinámica ambivalente, en efecto, es intrínseca al proceso de secularización que da origen a la modernidad), sino, como intentamos reflexionar, la irrupción de lo real colonial en el pensamiento europeo, el «retorno de lo reprimido» o el modo en que el planteo de Fernando Ortiz obliga a calibrar las teorías europeas de la secularización, en el marco más amplio de la crítica de la modernidad occidental ejercida desde la "periferia».

Es bien sabido cómo el pensamiento latinoamericano y caribeño no ha dejado de observar que la Conquista y colonización fueron la condición de posibilidad del sistema-mundo capitalista (Wallerstein), base material de la modernidad (cfr. Grüner 48). Para Julio Ramos, interesado en las síncopas de la secularización, "la paradoja es aún más implosiva: convertidos en mercancías", esos productos sagrados, como el tabaco, "provenientes de historias milenarias no-europeas, contribuyeron a la acumulación capitalista" (60). Contra toda idea unilateral y eurocéntrica 
sobre la modernidad y el supuesto carácter beneficioso del progreso que esta expandiría, el planteamiento pionero de Fernando Ortiz, retomado por Ramos, apunta a la retro-alimentación (el término aquí también es particularmente apropiado) del capitalismo y la colonización, lo secular-moderno y lo sagrado-arcaico, lo "civilizado» y lo «bárbaro». Según una formulación más precisa de Eduardo Grüner en su brillante estudio sobre la Revolución haitiana:

[...] la organización plenamente moderna y racional de las plantaciones -que podría satisfacer las más estrictas exigencias de la racionalización capitalista weberianapermitió por ejemplo, por primera vez en la historia, la producción a escala masiva y la consiguiente distribución mundial de mercancías tales como el azúcar, el café, el algodón y el tabaco que -como lo ha demostrado Sidney Mintz- se transformaron en factor fundamental de energización no solamente de las clases dominantes, sino sobre todo de la fuerza de trabajo proletaria de las primeras fábricas capitalistas en el "centro" (48-49).

Los africanos, en cuanto fuerza de trabajo esclava, constituyeron una mercancía clave para la optimización de este sistema de acumulación. Vale la pena destacar que la necesaria conjunción de la esclavitud afroamericana y el capitalismo fue establecida, no por azar, en la investigación doctoral del también caribeño Eric Williams, contemporánea del estudio de Ortiz y publicada, precisamente, como Capitalism and Slavery, en 1944.

La mutua implicación de la modernidad europea (sinónimo, a fin de cuentas, del capitalismo) y la esclavitud es, sin duda, la paradoja más trágicamente escandalosa en la historia occidental previa a Auschwitz. ¿Cómo se explica, en efecto, la convivencia del sistema de trabajo forzado de la plantación con la proclamada emancipación del hombre y el progreso: la cohabitación, en este mundo, de La oscuridad y las luces, como reza el título de Grüner que ahonda en esa relación inextricable desmantelada por Eric Williams? "Reducidos al estado de combustible biológico" -escribe luego el haitiano René Depestre-, fueron los denominados "negros», en las plantaciones y en los talleres de las Américas, quienes hicieron posible "el Siglo de las Luces, el vapor y la electricidad, así como otras conquistas de la revolución industrial del mundo moderno" (Depestre 9); vale decir, aquellas que alimentaron la fe en el progreso como perfecta vía para la realización plena del hombre, una vez que, bajo el proceso de secularización analizado por Max Weber, se hubieron rechazado "todos los medios mágico-sacramentales de búsqueda de la salvación" (ctd. en Marramao 59). 
Si, por un lado, teorizaciones como las de Fernando Ortiz, Eric Williams, René Depestre, el estadounidense Sidney Mintz o Eduardo Grüner vuelven visibles "las paradojas de la simultaneidad y de la multiplicidad temporal moderna", según la certera formulación de Julio Ramos, y obligan a revisar las fórmulas binarias, "el tipo de pensamiento dualista de las teorías de los sistemas-mundo que postula la 'periferia' como 'excepción' o lejanía (la palabra es de Lezama Lima) de un paradigma metropolitano" (60); por otro lado, estas conceptualizaciones conducen asimismo a calibrar la teoría de la secularización, con el objetivo de dar cuenta de las limitaciones de su versión eurocéntrica. En este sentido, además de que resulta necesario hablar de diversas modernidades o temporalidades, de modernizaciones incompletas o "desarrollos desiguales y combinados" (cfr. Grüner 2010), se vuelve sospechosa la ausencia de una reflexión sobre la incidencia de la Conquista, el colonialismo y el racismo en las mismas teorías de la secularización europea que explican la emergencia de la modernidad, tal como estas teorías son retomadas en la "genealogía" del fenómeno que ofrece el italiano Giacomo Marramao en un libro clave sobre el tema: Cielo y tierra. Genealogía de la secularización (1994).

Para entender el proceso de secularización, es decir, "el desarrollo histórico de la sociedad occidental moderna, a partir de sus raíces (judeo)cristianas" (Marramao 17), y su dinámica paradojal de mundanización/sacralización, por la cual lo sagrado no desaparece sino que se humaniza y encuentra refugio en esferas profanas, es ineludible recordar la tesis de Max Weber, expuesta en La ética protestante y el espíritu del capitalismo, respecto del protestantismo calvinista como base del «espíritu» del capitalismo y de la modernidad. A su vez, y tal como será analizado por Karl Löwith, en la moderna filosofía de la historia, en cuanto secularización de la "teología de la historia» de orientación cristiana y de su modelo escatológico, los atributos teológicos son transferidos al dinamismo histórico inmanente que, paradójicamente, es sacralizado: el hombre sustituye a Dios como sujeto absoluto de la historia, y la fe en el progreso, que para Löwith no es más que una ilusión ideológica, remplaza a la Providencia cristiana (cfr. Marramao 91-ss.). Pero, entonces, desde una periférica "lejanía" que, como sabemos, no es tal, sino el lado oscurecido en la moderna filosofía de la historia, surge la pregunta por los seres colonizados y deshumanizados, por los africanos esclavizados convertidos en mercancía para la acumulación del capital: ¿qué concepciones teológicas fueron también transferidas al mundo histórico, para que no todos los seres humanos, sino solo los 
hombres blancos, según esta ilusión, pudieran sustituir a Dios y asumirse como sujetos libres y soberanos?

La cuestión -teológica, filosófica, histórica- es sumamente compleja y, por supuesto, excede, en sumo grado, las posibilidades de una investigación puntual e individual desde el ámbito de los estudios culturales o la literatura afrocaribeña/afro(latino)americana. En lo que sigue, apenas atino a esbozar ciertas inquietudes, especialmente suscitadas por la lectura de algunos textos fundantes del anticolonialismo antillano de raigambre marxista, que, implícita o explícitamente, ponen de manifiesto la "blancura» de la moderna filosofía de la historia, sistema que -según se denuncia- justificó la convivencia, a primera vista oximorónica, de la institución de la esclavitud con la emancipación del hombre y el ideal del progreso como sustituto secularizado de la Providencia cristiana. A partir de estos planteos, cabe considerar que la racialización del progreso (su «blancura») es una de las modulaciones más evidentes de la paradójica dinámica secularización/sacralización que signa a la modernidad. Con su característico sarcasmo, Frantz Fanon en Piel negra, máscaras blancas (1952) deja esto al descubierto al alertar sobre (la buena fe de) las rehabilitaciones místicas de la negritud, que conceden a los negros un mundo esencial, espiritual, que el moderno hombre blanco ha perdido, mientras conserva el "mundo objetivo de las tierras, los bananos y las heveas" (106).

Pero es el haitiano René Depestrequien lúcidamente especifica el doble movimiento del proceso de secularización, a la luz del racismo moderno; es decir, la convivencia de una tendencia racionalizadora y cientificista con otra sacralizadora y mitificadora. En "Aventuras del negrismo en América Latina", al explorar el negrismo en el arte y la literatura, Depestre lo vincula con el racismo como fenómeno que emerge con el capitalismo, secularizando concepciones arcaicas y sagradas en torno del color de la piel:

Si los mitos, las supersticiones, los fetiches del color de la piel tienen raíces muy viejas en la religión, en los sistemas totémicos y clánicos, en el simbolismo ocultista y místico de los colores, el racismo, tal como lo conocemos, es una superestructura congénita del capitalismo. Es su proceso de fetichización de las relaciones sociales, de los productos del trabajo humano, el que se ha trasladado a las relaciones "raciales" en un cuadro colonial, entre amos "blancos" europeos y esclavos "negros" africanos" (25). 
Así, pues, la deconstrucción de lo que hemos denominado la racialización del progreso contribuiría a explicar la existencia de múltiples modernidades o temporalidades bajo el proceso de secularización, en relación con la dinámica colonizadora del sistema-mundo capitalista (las relaciones de producción y su división mundial del trabajo) y el lugar que en este sistema ocuparon los africanos convertidos en esclavos. En Los jacobinos negros (1938), su ensayo fundamental sobre la Revolución haitiana, C. L. R. James ronda constantemente esta cuestión, sintetizada en la rotunda afirmación de que "el fracaso de Toussaint fue una falla del iluminismo, no de la oscuridad" (217). La Revolución haitiana, precisamente a la luz de la Revolución francesa y de sus ideales de emancipación, expone de modo flagrante el mito de las luces y la mentira de la «universalidad» de los derechos del hombre. La institución de la esclavitud afroamericana, en el seno de la modernidad y en el contexto de un hito clave en el proceso de secularización occidental como lo fue la Revolución francesa, vuelve imperiosa la reflexión sobre ciertas operaciones de raíz teológica que han sido desatendidas por las teorías europeas de la secularización. El capital, o la colonialidad/modernidad/eurocentrada -para usar la fórmula del peruano Aníbal Quijano-, instrumentaliza concepciones cristianas que, lejos de desaparecer, se transforman y devienen funcionales al progreso eurocéntrico «blanco». Como bien argumenta Depestre, sin los fundamentos socioeconómicos del racismo:

la leyenda tradicional del diablo "negro" en la iconografía cristiana, la del sacerdote Jean, el mito bíblico del hijo de Cham, y otras supersticiones del pasado más remoto, no hubieran tenido una vida larga y resistente como la de los clichés que la colonización moderna ha forjado con el asunto del color de los hombres (25).

El proceso de secularización, entonces, implicó tanto la "racionalización del dominio sobre el mundo", según la definición de un estudioso de Max Weber (Schluchter ctd. en Marramao 55-56), como su racialización: la transformación de conceptos teológicos en una ideología "racionalista» sobre la diferencia racial. En su ya citado La oscuridad y las luces, Eduardo Grüner aporta a la comprensión del fenómeno cuando, al ahondar en la genealogía del racismo moderno, se remonta al Renacimiento (en el contexto de la expulsión o conversión forzada de árabes y judíos) y a la difusión - posibilitada por la Reforma y la Biblia impresa- de los mitos acerca de las "maldiciones de Noé", la cual explica la autopercepción identitaria de los europeos 
como "descendientes de 'Europa' o Japhet, y por lo tanto algo totalmente diferente y separado a las otras dos ramas 'históricas' (en rigor, mítico-bíblicas) de la humanidad [...], los de Shem ('semitas') y de 'Ham' (los 'negros' hamitas)" (Grüner 218). De acuerdo con un pasaje veterotestamentario, Ham (África), el tercer hijo de Noé, cargaba con un castigo divino por haberse burlado de su padre: por ello, todos sus descendientes habían sido condenados a servir como esclavos de los descendientes de Shem y Japhet (Grüner 108).

Si, por un lado, han sido reflexiones como la de René Depestre las que han servido al desmantelamiento del racismo como superestructura del capitalismo, y, de modo más general, puede afirmarse que el ensayo anticolonialista caribeño, con exponentes como C. L. R. James, Aimé Césaire, Frantz Fanon o George Lamming, se caracteriza por la apropiación crítica de un aparato de pensamiento marxista que permite deconstruir los mitos occidentales (el progreso, la raza, los ideales «universales» de la Revolución francesa), por otro lado, no es menos cierto que en estos autores las creencias retornan a través del imaginario emancipatorio de la negritud y la experiencia política (secularizada, resacralizada) de la diáspora africana como sujeto revolucionario. Porque, como bien piensa Fanon, politizar a las masas no es "dirigirles esporádicamente un discurso político", sino "abrir el espíritu, despertar el espíritu, dar a luz el espíritu. Es, como decía Césaire, "inventar almas'”, y hacerles comprender a las masas "que el demiurgo es el pueblo y que las manos mágicas no son en definitiva sino las manos del pueblo" (Los condenados 97-98).

Mientras el anticolonialismo antillano de matriz marxista mantiene a raya las mistificaciones de la razón occidental, e incluso alerta sobre los peligros de la negritud erigida como un nuevo mito racial (a la inversa), el ensayo no puede dejar de imaginar un futuro de libertad y justicia que se alcanzaría, incluso, por la vía de lo irracional: es el caso, por citar un ejemplo paradigmático, de Fanon y la violencia emancipatoria como secularización de lo ritual africano, que -como bien interpretó Sartre en el prólogo a Los condenados de la tierra (1961)restituye a los colonizados la humanidad que les fue arrebatada ${ }^{2}$. Los argelinos, escribe Fanon, han descubierto que "el colonialismo no es una máquina de pensar, no es un cuerpo dotado de razón. Es la violencia en estado de naturaleza y no puede inclinarse sino ante una violencia mayor" (Los condenados 30).

\footnotetext{
2 Escribe Sartre: "esa violencia irreprimible [...] no es una absurda tempestad ni la insurrección de instintos salvajes ni siquiera un efecto del resentimiento: es el hombre mismo reintegrándose" (12).
} 
Ante el atropello del colonizador que desmiente todo contrato social y deja al descubierto que el proceso de secularización no ha barrido con las creencias, sino que, como observó Walter Benjamin, ha erigido al capitalismo como una religión, la violencia del colonizado aparece como una profanación: se toman los derechos por la fuerza, se expropian los ideales de la modernidad, se sacralizan el caos y la rebelión. En el gracioso intercambio entre el mulato Ariel y el negro Calibán en Une tempête (1969) de Aimé Césaire, quienes representan, respectivamente, el modo pacífico y la vía violenta de conquista de la libertad (la opción entre Martin Luther King, por un lado, y el Black Power o los Black Panthers herederos de Fanon y Malcolm X, por el otro) ${ }^{3}$, el extremismo de Calibán es presentado como acto revolucionario, de ética y justicia trascendental:

Ariel: ¿Y entonces qué queda? ¿La guerra? Sabés que en ese juego Próspero es imbatible.

Calibán: Más vale la muerte que la humillación y la injusticia. Además, de todas maneras, yo voy a tener la última palabra... Salvo que le pertenezca a la nada. El día que tenga la sensación de que todo está perdido, dejame robar algunos barriles de tu pólvora infernal, y desde lo alto del empíreo adonde te gusta planear, verás saltar por los aires esta isla, mi bien, mi obra, con, espero, Próspero y yo entre los deshechos. Ojalá te gusten los fuegos artificiales: van a estar firmados Calibán (Una tempestad 2, 1, 81, 83)4.

Desde un punto de vista exterior a Occidente, la dinámica paradojal secularizadora/sacralizadora de la modernidad es leída en conjunción con el racismo, y el desencantamiento del mundo (Max Weber) deviene un simultáneo "encantamiento del bárbaro", según el haitiano Laënnec Hurbon (38). En El bárbaro imaginario -un planteo clave para 'contrapuntear' el proceso de racialización con aquel de la racionalización moderna-,

\footnotetext{
${ }^{3}$ Césaire mismo ofrece esa lectura: "Ante la dominación de Próspero, hay diversos modos de reaccionar: (...). Está Martin Luther King y Malcolm X y las Panteras Negras. Simplificando, Calibán sería la violencia, Ariel representaría la tendencia no-violenta" (Béloux 31).

${ }^{4}$ Cito el original de la edición bilingüe de El 8vo. Loco Ediciones del 2011:

"Ariel: Alors, que reste-t-il? La guerre? Et tu sais qu'à ce jeu-là Prospero est imbattable.

Calibán: Mieux vaut la mort que l'humiliation et l'injustice... D'ailleurs, de toute manière, le dernier mot m'appartiendra... À moins qu'il n'appartienne au néant. Le jour où j'aurai le sentiment que tout est perdu, laisse-moi voler quelques barils de sa poudre infernale, et cette île, mon bien, mon oeuvre, du haut de l'empyrée où tu aimes planer, tu la verras sauter dans les airs, avec, je l'espère, Prospero et moi dans les débris. J'espère que tu goûteras le feu d'artifice: ce sera signé Caliban" (Césaire 80, 82).
} 
Hurbon advierte que, en lugar de un encuentro con la alteridad (la novedad del mundo no occidental), la Conquista inaugura la "desbarbarización del bárbaro", y, una vez disuelta la otredad del «otro», llena con lo imaginario aquello que define como vacío (13).

Este fenómeno iniciado por la colonialidad/modernidad/eurocentrada, concebido a su vez por Aníbal Quijano como una "mistificación metafísica de las relaciones humanas con el resto del universo", se nutriría, entonces, por un lado, de la larga y residual tradición del imaginario (judeo)cristiano y, por el otro, de lo que el intelectual peruano define como el "nuevo y radical dualismo cartesiano, que separa la 'razón' y la 'naturaleza'”, y donde la idea de «raza» es parte inherente de la «naturaleza» y la ética productivista que justifica la dominación de esta última se aplica también a la explotación de las «razas inferiores» (83).

No por azar, los mismos escritores que en el Caribe han puesto en entredicho los mitos occidentales de una modernidad benéfica de alcance universal, y que implícita o explícitamente han vuelto manifiesta la "blancura» de la moderna filosofía de la historia, han encontrado en La tempestad de Shakespeare un núcleo de sentido religador, una especie de fábula paradigmática de la Conquista, los mismos comienzos de la colonialidad/modernidad/eurocentrada. Édouard Glissant, en su capital El discurso antillano, explica con precisión la relevancia filosófica que adquiere el drama shakespeareano en aquel movimiento inicial en el que la literatura y la historia organizan "la Totalidad en sistema" (188-189). Shakespeare, para Glissant, elabora grandiosamente la cuestión "cosmo-metafísica de la legitimidad" (188-189), que sanciona el equilibrio naturaleza-cultura y que, abandonando las alquimias medievales, inaugura la modernidad. Pero en el equilibrio-totalidad se instala de modo manifiesto, según Glissant, una jerarquía: "Calibán-naturaleza se opone desde abajo a Próspero-cultura. Así, en La tempestad, la legitimidad de Próspero está vinculada a su superioridad y se convierte en legitimidad de Occidente" (El discurso... 188-189). Si en la literatura Shakespeare valida el dominio de los pueblos de la escritura, en la historia esa jerarquización se inicia con Hegel, y es a partir de la lucha de los pueblos orales contra la legitimidad de Occidente que se develan sus mecanismos totalitarios, la «doble aspiración» de una Historia con H mayúscula, excluyente de las historias no concomitantes con Occidente, y de una literatura "sacralizada en el absoluto del signo escrito" (Glissant, El discurso... 190). 


\section{El limbo de la historia}

Como sabemos, la sanción de Hegel, con su filosofía de la historia europea frente a la a-historia de América o la pre-historia de África, ha sido el blanco de ataque del pensamiento anticolonialista, la misma imagen del infierno para muchos latinoamericanos ${ }^{5}$ y antillanos como Glissant, Fanon o Césaire, solo superada en el Caribe por la condena del inglés J. A. Froude a las fútiles Indias Occidentales "sin historia», una postura que en los años 60 era suscripta con provocación por V. S. Naipaul en The Middle Passage (1962). El recientemente fallecido intelectual barbadense Kamau Brathwaite, historiador de profesión, además de destacado escritor, es, sin duda, quien mejor ha representado la resistencia a la filosofía colonial de Occidente en las Antillas anglófonas, y quien con más ahínco ha recusado a la historiografía caribeña eurocentrada y, en particular, a sus voceros más conspicuos (cfr. Brathwaite, The development). Naipaul, por ejemplo, de modo lamentable para Brathwaite, sostenía en The Middle Passage que nada había sido creado en las Antillas, e incluía como epígrafe las siguientes palabras de Froude, extraídas de The English in The West Indies (1887): "No ha habido santo en las Antillas desde Las Casas, ningún héroe a menos que el entusiasmo filonegro quiera ver uno en Toussaint. No existe aquí un pueblo en el verdadero sentido de la palabra, con carácter y objetivos propios" (ctd. en Naipaul [mi traducción]).

Así, pues, en cuanto lugar común del ensayo caribeño -lieu commun en la fórmula glissantiana (Philosophie... 25) $-{ }^{6}$ emergen aquellas lecturas «negras» de la filosofía (blanca) de la historia que cuestionan su racionalidad con arreglo a fines de expropiación, su utilitarismo deshumanizante y su instrumentalización de las vidas ajenas, su poder colonial: ya Césaire en su fundador Discurso sobre el colonialismo denuncia a los intelectuales europeos por "su falsa objetividad, su chovinismo, su racismo hipocritón, su viciosa pasión para negar a las razas no blancas, particularmente a las razas melaninosas, todo mérito, su monomanía para monopolizar toda gloria en beneficio de la propia" (333).

\footnotetext{
5 Es Liliana Weinberg, al explorar los «problemas» del ensayo latinoamericano (sujeto a "condiciones de inteligibilidad» regidas extraterritorialmente), quien destaca la repetida imagen del infierno (la incomunicación), que para muchos ensayistas representa el "autoritarismo infernal» de Hegel, "el que detenta las condiciones de legitimidad del conocimiento" (63).

${ }^{6}$ Cfr., de mi autoría, "El ensayo que se repite o el Caribe como lugar-común (Antonio Benítez Rojo, Édouard Glissant, Kamau Brathwaite)". Anclajes (La Pampa). Dic. 2014: 19-31. Impreso.
} 
Mientras tanto, de modo simultáneo, la poesía y la narrativa caribeñas, en sus diversas lenguas de expresión, han puesto en entredicho la linealidad de la lógica temporal occidental, las concepciones unilaterales y unidireccionales del tiempo histórico, su orden secuencial de causas y efectos, la misma idea de progreso. En una brillante lectura, el crítico Alex Gil ha analizado, en un modo benjaminiano, cómo el Cuaderno de un retorno al país natal de Césaire no solo "reclama la voz ahogada del pasado; intenta rediseñar, además, la práctica misma de la historia con el fin de asegurar un espacio crítico distinto al de la Modernidad que lo excluyó a priori" (41). Es la opción poética de Césaire, en contraste con la práctica científica y a diferencia de otros escritores y artistas antillanos que recurren a la historia oral o la leyenda, la que para Gil "nos permite leer la historia donde la historia está ausente, tanto de la educación como de la conciencia", pues aparece inscripta, a través de la metáfora, en la condición material de la gente, "en los cuerpos cotidianos de aquellos despreciados por la Historia" (58-59). Así es como Gil lee el conmovedor pasaje del Cahier sobre el pequeño négrillon somnolent en la escuela: "El hambre del niño se ahoga tal como lo hace el negrero liberado, su voz olvidada en el turbio fondo del mar. Un hambre que tuvo lugar, y un ahogarse que tiene lugar, conspiran conjuntamente a través de lo fantasmal" (58-59).

porque es en los pantanos del hambre donde se ha hundido su voz de inanición (una palabra-una-sola-palabra y os-libro-de-la-reina-Blanca-de-Castilla, una palabra-unasola-palabra, ved-ese-pequeño-salvaje-que-no-sabe-ni-uno-de-los-diez-mandamientos-deDios), porque su voz se olvida en los pantanos del hambre,

y no se puede sacar nada, verdaderamente nada, de ese pequeño granuja, salvo un hambre que ya no sabe trepar por las jarcias de su voz, (Césaire, Cuaderno de... 30)7.

El recurso a la metáfora, por la que se produce el "benéfico retorno de lo reprimido", nos habla así de un tiempo impredecible, dislocado, representado por el movimiento en espiral o

\footnotetext{
7 En el original: "car c'est dans les marais de la faim que s'est enlisée sa voix d'inanition (un mot-un-seul-mot et je-vous-en-tiens-quitte-de lareineBlanche-de-Castille, un-mot-un-seul-mot, voyez-vous-cepetit-sauvage-qui-ne-saitpas-un-seul-des-dix-commandements-de-Dieu) / car sa voix s'oublie dans les marais de la faim, et il/ n'y a rien, rien à tirer vraiment de ce petit vaurien,/ qu'une faim qui ne sait plus grimper aux agrés de sa voix".
} 
por la paradójica immobile verrition, sin duda, la palabra más enigmática y significativa del diccionario -y del imaginario temporal- cesairiano ${ }^{8}$

Con fuerte anclaje en la ruptura de las convenciones ideológicas y estéticas efectuada por los ismos europeos de vanguardia, también la literatura latinoamericana, como sabemos, ha hecho de los desvíos y las alteraciones de la temporalidad una de sus marcas distintivas, aportando al desarrollo de dos subgéneros narrativos de gran trascendencia desde el período posvanguardista: el fantástico y el realismo mágico. Dada la abundancia de literatura especializada en torno de estas modalidades, baste aquí con mencionar la oportuna lectura política de Steve Stern sobre el tratamiento del tiempo narrativo en autores canónicos como Cortázar, García Márquez y Carpentier, cuyos "trucos del tiempo" convierten la historia "en un espíritu incansable que permea el presente en lugar que ser un capítulo cerrado o un prólogo del presente" (139 [mi traducción]). Para Stern, la herencia colonial viva, cargada con frecuencia de sentidos políticos, desacomoda las nociones progresivas de la marcha de la historia. Tanto el tiempo inmóvil, la coexistencia de versiones unilineales del tiempo, o el movimiento circular en el que, a pesar de la ilusión del progreso, se retorna a los principios, constituyen procedimientos afines que, haciendo hincapié en el ciclo y la recurrencia, la continuidad y el movimiento múltiple (hacia adelante, hacia atrás, por inercia) "compiten o vuelven superficiales o ilusorias las nociones más familiares de cambio, movimiento hacia adelante o progreso en el tiempo" (139).

Un caso paradigmático en la literatura del Caribe hispánico es, por supuesto, el Viaje a la semilla de Carpentier (1971); Stern, no obstante, se detiene a analizar otros "trucos del tiempo" en la más conocida novela del cubano: Los pasos perdidos (1953), claro antecedente de la ficción mágico-realista de García Márquez. En el Caribe no hispánico, la afinidad de los escritores con estas «sensibilidades históricas latinoamericanas», como las llama Stern, fue explícitamente asumida, en especial por los autores coetáneos del llamado boom y quienes adoptaron el legado de Carpentier y García Márquez, reivindicando o explorando en su propia producción las

\footnotetext{
${ }^{8}$ Gil se concentra en el hermético término «verrition» al final del poema («Et le grand trou noir où je voulais me noyer l'autre lune/ C'est là que je veux pêcher maintenant/ la langue maléfique de la nuit en son immobile verrition!»), y recupera uno de sus sentidos, "una especie de movimiento giratorio, en remolino", a partir de un neologismo aportado por un gastrónomo francés del siglo XIX, que se remontaría al latín "verro", para designar un movimiento alimentario en los animales, "cuando la lengua se curva hacia arriba o hacia abajo. [...] para recoger los restos de comida [... E En su barrido, la lengua también sugiere una vuelta o retour, si se quiere..." (48).
} 
posibilidades abiertas de lo «real maravilloso» o el "realismo mágico», desde George Lamming ${ }^{9}$, Wilson Harris o Kamau Brathwaite (que incluso dedicó al tema dos importantes volúmenes, Magical Realism, en el año 2002) en el área anglófona, o René Depestre, Édouard Glissant, Maryse Condé, o el más contemporáneo Gary Victor en las Antillas francófonas.

En este sentido, para terminar, resultan sumamente ilustrativas las reflexiones del guyanés Wilson Harris en su clásico ensayo History, Fable and Myth in the Caribbean and Guianas, quien al indagar en los vestigios subterráneos, divergentes e inconscientes del pasado, que se hacen presentes en la "lógica intuitiva» de los escritores y artistas caribeños, encuentra la posibilidad de una filosofía de la historia "en las artes de la imaginación" (6) ${ }^{10}$. Harris comienza por denunciar el determinismo de muchos historiadores y escritores caribeños, aun de aquellos que, desde una dialéctica marxista, como el trinitario C. L. R. James o la guyanesa Elsa Goveia, más han aportado a "una filosofía de la historia para el Tercer Mundo": "militantes y críticos del imperialismo, han sido víctimas, en otro sentido, del mismo imperialismo que parecen denunciar. No tienen un criterio para las artes de una originalidad que surge de la era del limbo y la historia que escriben no contiene un tiempo interno" (10). En el limbo ${ }^{11}$, precisamente, encuentra Harris una clave de la "sutil dislocación o metamorfosis original dentro de la cárcel del tiempo", que para Goveia es "la vieja herencia de la esclavitud" (30). Esa danza popular, por tanto tiempo censurada, recreada maravillosamente en el poema "Caliban» de Kamau Brathwaite, constituye -junto con otras prácticas afro e indoamericanas- un ejemplo paradigmático de la "alteración o

\footnotetext{
${ }^{9}$ En una entrevista de 1990, Lamming relaciona, además, la literatura del sur de los Estados Unidos con la escritura latinoamericana y caribeña: "Faulkner, Márquez, Lamming, Césaire; debe hacerse un estudio comparado de esa carga particular de la imaginación". La última novela Natives of My Person (1972) de Lamming se emparenta con el tipo de ficción histórica de Carpentier y con el sentido político de su narrativa o la de García Márquez, como él mismo afirma en la entrevista: "Ya sea Márquez o Carpentier, no se trata de la exploración de una conciencia individual. Está supeditada al movimiento de la sociedad como una totalidad. (...) Márquez escribe sobre la totalidad de Colombia y de Latinoamérica, no sólo sobre ese general en particular o esa familia en particular. Eso es muy fuerte en Los pasos perdidos de Carpentier y en El reino de este mundo. Creo que tiene que ver con una urgencia histórica. (...) Ha afectado también la forma de la narrativa. (...) no encaja fácilmente con lo que serían, digamos, las formas convencionales de la narrativa en Europa o en áreas de Norteamérica. (...) es posible ver también la influencia persistente de lo que llamaría sociedad de plantación" (Goddard, párr. 10).

${ }^{10}$ De aquí en adelante, las traducciones del texto de Harris me pertenecen.

${ }^{11}$ Harris describe el baile recuperando las conexiones - previamente establecidas- con la figura popular de Anancy en el poema "Caliban" (Islands, 1969) de Brathwaite: "El danzante del limbo pasa por debajo de una barra que gradualmente se baja, hasta que parece quedar solo un pequeño espacio por el que pasa, con sus miembros extendidos, como una araña. Se dice que el Limbo nació en los barcos negreros del Pasaje Medio. Había tan poco espacio que los esclavos se contorsionaban hasta volverse arañas humanas" (7).
} 
dialéctica de la alteración" que a Harris se le presenta "como la piedra angular para una filosofía de la historia en el Tercer mundo del Caribe" (32). Como Harris explica, el limbo

no es el recuerdo total de un pasado africano puesto que el pasado africano en términos de soberanía o soberanías tribales fue modificado o traumáticamente eclipsado con el Pasaje Medio y en las generaciones de cambio que siguieron. El limbo fue más bien el renacimiento de un nuevo cuerpo de sensibilidad que podía traducir y acomodar los legados africanos y demás legados en una nueva arquitectura de culturas. Por ejemplo el tema del miembro fantasma -la re-unión del hombre o dios desmembrado- posee resonancias arquetípicas que abarcan al Osiris egipcio, al Cristo resucitado y a la deidad de múltiples brazos de India (8).

Como "arte de compensación que busca re-presentar el desmembramiento de tribus [...] e invocar al mismo tiempo una curiosa reintegración psíquica de las partes del dios o los dioses muertos", el limbo desmiente el documentarismo histórico y la literatura de protesta que ve al Caribe completamente despojado y explotado (Harris 9). Así, en lugar de manifestar una visión monolítica y continua del tiempo, el limbo apunta a las interrupciones, dislocaciones y coexistencias, y a "la originalidad del hombre como animal productor de civilización que puede alterar el complejo arquitectural de una época" (Harris 32). Moviéndose por debajo, el limbo, a través de estas lecturas, metaforiza de modo ejemplar los subter-fugios de la literatura y el arte caribeños, los cimarroneos y las vías de escape alternativas a la filosofía de la historia occidental.

\section{A modo de conclusión}

Aun guiados por la lógica intuitiva de las artes de la imaginación, está claro que los intelectuales caribeños no solo desarrollan rigurosas deconstrucciones de los mitos occidentales (el progreso, la raza, "las luces») en su textos ensayísticos, o ingeniosas (y contrateleológicas) construcciones temporales -mítico o mágico realistas- en sus narrativas; se aprovechan estratégicamente, además, de la polisemia del lenguaje poético para apuntalar su crítica a la modernidad europea y sus paradigmas filosóficos e historiográficos. Así, el «limbo» de Kamau Brathwaite, en la tercera sección de su poema «Caliban» (Islands, 1969), podrá también aludir al estado o sitio donde, según la teología cristiana, residen los inocentes de la historia, aquellos 
que, no habiendo cometido pecado alguno, se encuentran sujetos a la misericordia de Dios. En el poema, el palo del limbo es el símbolo de la violencia colonial, la imposición de la oscuridad, el látigo y el silencio, un estado fantasmático que coloca a los negros esclavos -quienes, como los niños del limbo, fueron infantilizados o considerados sin razón por el Occidente cristianoen una frontera cercana al infierno, y que en este caso es el espacio del barco negrero: "And limbo stick is the silence in front of me / limbol/ limbo/ limbo like me/ limbol limbo like mel long dark night is the silence in front of me/ limbo/ limbo like me// stick hit sound/ and the ship like it ready// stick hit sound/ and the dark still steady// limbo/ limbo like me// long dark deck and the water surrounding me/ long dark deck and the silence is over me// limbo/ limbo like me// stick is the whip/ and the dark deck is slavery..." (Brathwaite, The arrivants 194).

En la historia secular, según esta es iluminada -o dislocada- por el poema, el destino esclavista en la tierra es un limbo, y el yo lírico, el Calibán de Shakespeare ya deconstruido como sujeto colonizado y racializado, volverá a profanar los significados cristianos para conferirse una posibilidad de liberación: "sun coming up/ and the drummers are praising me// out of the dark/ and the dumb gods are raising me// up/ up/ up// and the music is saving me// hot/ slow/ step// on the burning ground" (Brathwaite, The arrivants 195). Transfigurado el limbo finalmente en ritmo danzario, «cuerpo de sensibilidad» que, como dijera Harris, sincréticamente acomoda los diversos legados en una «nueva arquitectura de culturas», la poesía de Brathwaite - paradigmática en su continuo movimiento de profanación y resacralizaciónpone maravillosamente en imágenes la experiencia política, y trascendental, de la negritud afroantillana.

\section{Referencias}

Brathwaite, Edward. The Development of Creole Society in Jamaica 1770-1820. Oxford: Clarendon Press, 1971. Impreso.

Brathwaite, Edward. The Arrivants. A New World Trilogy (Rights of Passage, Islands, Masks). London: Oxford University Press, 1973. Impreso.

Béloux, François. "Un poète politique: Aimé Césaire". Magazine Littéraire. Nov. 1969: 27-32. Impreso.

Césaire, Aimé. Cuaderno de un retorno al país natal (edición bilingüe). Prólogo y trad. al español de Agustí Bartra. México D. F.: Ediciones Era, 1969 [1939]. Impreso. 
Césaire, Aimé. "Discurso sobre el colonialismo". Para leer a Aimé Césaire. Trad. Arturo Vázquez Barrón y Roberto Rueda Monreal, selección y presentación de Philippe Ollé-Laprune. México: Fondo de Cultura Económica, 2008. 313-355. Impreso.

Césaire, Aimé. Una tempestad (edición bilingüe). Trad. del francés de Ana Ojeda, prólogo de Rocco Carbone y Leonardo Eiff. Buenos Aires: El 8vo. Loco, 2011. Impreso.

Depestre, René. Buenos días y adiós a la negritud. La Habana: Casa de las Américas (Cuadernos Casa 29), 1986. Impreso.

Fanon, Frantz. Piel negra, máscaras blancas. Trad. de Ángel Abad. Buenos Aires: Editorial Abraxas, 1973. Impreso.

Fanon, Frantz. Los condenados de la tierra. Trad. Julieta Campos, prefacio de Jean-Paul Sartre, epílogo de Gérard Chaliand. México: FCE, 1983 [1963]. Impreso.

Gil, Alex. "El gran agujero negro: a la caza del fantasma en Cahier d'un retour au pays natal'. Estudios. Ene-jun. 2013: 41-67. Impreso.

Glissant, Édouard. El discurso antillano. Trad. A. M. Boadas y A. Hernández. Caracas: Monte Ávila, 2005 [1981]. Impreso.

Glissant, Édouard. Philosophie de la relation. Poésie en étendue. Paris : Gallimard, 2009. Impreso.

Goddard, Horace. (2008). "Interview with George Lamming. [Montreal, April 7, 1990]". Kola. A Black Literary Magazine. Web. 22 mar. 22. 2008 <http://www.highbeam.com/doc/1G1-180798299.html>. Digital.

Grüner, Eduardo. La oscuridad y las luces. Capitalismo, cultura y revolución. Buenos Aires: Edhasa, 2010. Impreso.

Harris, Wilson. "History, Fable and Myth in the Caribbean and Guianas". Caribbean Quarterly. Jun. 1970: 1-32. Impreso.

Hurbon, Laënnec. El bárbaro imaginario. Trad. Jorge Padín Videla. México: FCE, 1993. Impreso. James, C. L. R. Los jacobinos negros. Toussaint L 'Ouverture y la revolución de Saint-Domingue. Trad. Rosa López Oceguera, introducción de John Bracey. La Habana: Casa de las Américas, 2010. Impreso.

Marramao, Giacomo. Cielo y tierra. Genealogía de la secularización, trad. de Pedro Miguel García Fraile, Buenos Aires-Barcelona-México, Paidós. 1998. Impreso. 
Naipaul, Vidia. The Middle Passage. Impressions of five societies, British, French and Dutch, in the West Indies and South America. London: André Deutsch, 1974 [1962]. Impreso.

Quijano, Aníbal. “'Bien Vivir': entre el 'desarrollo' y la des/colonialidad del poder”. Ecuador Debate. Dic. 2011: 77-87. Impreso.

Ramos, Julio. "Descarga acústica". Papel máquina. 2010. 49-77. Impreso.

Sartre, Jean-Paul. "Prefacio" a Frantz Fanon. Los condenados de la tierra. Trad. Julieta Campos. Buenos Aires: $\quad 1983$ [1963]. 5-16. $<$ https://www.lahaine.org/est_espanol.php/libro-los-condenados-de-la-tierra $>$. Digital.

Stern, Steve. "The Tricks of Time: Colonial Legacies and Historical Sensibilities in Latin America". Colonial Legacies. The Problem of Persistence in Latin American History. Ed. Jeremy Adelman. New York \& London: Routledge, 1999. 135-150. Impreso.

Weinberg, Liliana. El ensayo, entre el paraíso y el infierno. México: UNAM-FCE, 2001. Impreso. 